\title{
Estágio curricular supervisionado em Educação Física: aproximações com a teoria de Norbert Elias
}

Práctica curricular supervisada en Educación Física: cercanías con la teoría de Norbert Elias Supervised Teaching Practice in Physical Education: similarities with the theory by Norbert Elias

\section{Volumen 18, Número 3 \\ Setiembre-Diciembre}

pp. $1-20$

\section{Este número se publica el 1 de setiembre de 2018 \\ DOI: https://doi.org/10.15517/aie.v18i3.34433}

\author{
Arestides Pereira da Silva Júnior \\ Amauri Aparecido Bássoli de Oliveira
}

Revista indizada en REDALYC, $\underline{\text { SCIELO }}$

Revista distribuida en las bases de datos:

\section{LATINDEX, DOAJ, REDIB, IRESIE, CLASE, DIALNET, SHERPA/ROMEO, QUALIS-CAPES, MIAR}

Revista registrada en los directorios:

ULRICH'S, $\underline{\text { REDIE}}, \underline{\text { RINACE}}, \underline{\text { OEI }}$ MAESTROTECA, PREAL, $\underline{\text { CLACSO }}$ 


\title{
Estágio curricular supervisionado em Educação Física: aproximações com a teoria de Norbert Elias
}

Práctica curricular supervisada en Educación Física: cercanías con la teoría de Norbert Elias Supervised Teaching Practice in Physical Education: similarities with the theory by Norbert Elias

\section{Arestides Pereira da Silva Júnior ${ }^{1}$ Amauri Aparecido Bássoli de Oliveira²}

\begin{abstract}
Resumo: Esse ensaio tem como objetivo discutir o Estágio Curricular Supervisionado na formação inicial de professores de Educação Física na perspectiva da Teoria Configuracional de Norbert Elias. O modelo de configurações proposto na teoria Elisiana, permitiu constatar que a universidade e a escola são vistas como teias complexas de relações interdependentes e de poder, destacando que o estágio deve constituir-se como um espaço capaz de promover relações mais próximas dentre os elementos que fazem parte deste processo de ensino na formação inicial dos futuros professores de Educação Física. O estudo apresentou incursões $e$ apontamentos de propostas que valorizem e aproximem os elementos constitutivos do estágio (professores da universidade e da escola e estagiários), no intuito de possibilitar as instruções, as trocas de conhecimentos, os relacionamentos e as reflexões sobre a atuação pedagógica. Conclui-se que o Estágio Curricular Supervisionado é uma prática dinâmica, complexa e de suma importância na formação inicial dos professores de Educação Física. No entanto, as discussões apresentadas no estudo e referendadas a partir do referencial teórico de Norbert Elias, reforçam a importância das configurações e das relações de indivíduos interdependentes. A partir das reflexões e análises realizadas, sugere-se a realização de pesquisas de campo, diretamente com os agentes evolvidos com o Estágio Curricular Supervisionado na Educação Física, no intuito de constatar tais relações/incursões.
\end{abstract}

Palavras-chave: universidade, formação, educação física.

Resumen: Este ensayo tiene como objetivo discutir la Práctica Curricular Supervisada en la formación inicial de docentes de Educación Física en la perspectiva de la Teoría Configuracional de Norbert Elias. El modelo de configuraciones propuesto en la teoría Elisiana permitió constatar que la universidad y la escuela son vistas con entramados complejos de relaciones interdependientes y de poder. Se destaca que la Práctica debe constituirse como un espacio capaz de promover relaciones más próximas entre los elementos que forman parte de este proceso de enseñanza en la formación inicial de los futuros docentes de Educación Física. El estudio presentó incursiones y apuntes de propuestas que valoren y acerquen los elementos constitutivos de la práctica (docentes de la universidad y de la escuela y prácticas), con la intención de posibilitar las instrucciones, los cambios de conocimientos, las relaciones y las reflexiones sobre la actuación pedagógica. Se concluye que la Práctica Curricular Supervisada es una práctica dinámica, compleja y de suma importancia en la formación inicial del cuerpo docente de Educación Física. Sin embargo, las discusiones presentadas en el estudio y refrendadas, a partir del referencial teórico de Norbert Elias, refuerzan la importancia de las configuraciones y de las relaciones de individuos interdependientes. A partir de las reflexiones y análisis realizados, se sugiere la realización de estudios de campo, directamente con los agentes involucrados en la Práctica Curricular Supervisada en la Educación Física, para constatar tales relaciones/incursiones.

Palabras clave: universidad, formación, educación física.

\footnotetext{
1 Professor da Universidade Estadual do Oeste do Paraná, Brasil.

Dirección electrónica: arestidesjunior2000@yahoo.com.br

2 Professor da Universidade Estadual de Maringá, Brasil. Dirección electrónica: amauribassoli@gmail.com
}

Ensayo recibido: 5 de marzo, 2018

Enviado a corrección: 19 de julio, 2018

Aprobado: 27 de agosto, 2018 
Abstract: The aim of this assay is to discuss the influence of Supervised Teaching Practice on the initial training of Physical Education teachers based on the concept of configuration in Norbert Elias' sociological theory. According to the configuration model suggested by the Elisian theory, the university and schools are complex nets of interdependent power relations. It highlights that teaching practice must be capable of promoting closer relations among elements that participate in the learning process during the initial training of future Physical Education teachers. The study presented the development of propositions to value and approximate teaching practice elements (college professors, school teachers and trainee students). The aim of these propositions is to enable instructions, knowledge exchange, relationships and reflections about pedagogical actions. Therefore, Supervised Teaching Practice is a dynamic, complex and extremely relevant part of the initial training of Physical Education teachers. However, discussions presented in the study and referenced by Norbert Elias' theory reinforce the importance of configurations of, and relationships between, interdependent individuals. From the reflections and analyzes carried out, it was possible suggesting further field research with agents involved in the Supervised Teaching Practice in Physical Education, in order to assess such relations/incursions.

Keywords: university, formation, physical education.

\section{Introdução ${ }^{3}$}

Quando é que começamos a ser professores? Talvez a resposta tenha sua origem nas vivências de brincadeiras da infância, por influência dos pais, na escolha pelo curso de licenciatura, dentre outras. No entanto, em muitos casos é no Estágio Curricular Supervisionado (ECS) o momento em que o futuro professor experimenta as primeiras vivências com a docência no contexto escolar e se dá conta do "chão" no qual pisará ao longo da sua trajetória profissional. É o momento em que ele se defronta com situações de conflitos, tensões, disputas, relações de poder e outros acontecimentos inusitados que possam surgir e que, por vezes, fazem com que os acadêmicos reflitam se a escolha pela docência foi a melhor decisão tomada.

Alguns chegam a pensar em desistir, ou até mesmo desistem, outros desanimam-se com a realidade apresentada, mas há aqueles que se entusiasmam e, inclusive, se apaixonam pelos desafios da prática docente e as modestas retribuições de reconhecimento no campo da atuação pedagógica. Assim, esse momento da formação inicial se torna fundamental, tanto pelas experiências vivenciadas no processo de ensino aprendizagem, quanto pela possibilidade de estabelecer relações mais próximas com o contexto de atuação.

Nessa direção, Aroeira (2014) entende o ECS como um processo formativo que fomenta parcerias capazes de promover relações interativas, dinâmicas e colaborativas entre universidade e escola, trazendo aos estagiários a possibilidade de tomar atitudes mais ativas, autônomas e conscientes. Complementando, a autora afirma que a aproximação

\footnotetext{
3 A pesquisa recebeu apoio financeiro da Fundação Araucária de Apoio ao Desenvolvimento Científico e Tecnológico do Estado do Paraná e da Coordenação de Aperfeiçoamento de Pessoal de Nível Superior (CAPES) por meio de bolsas de estudo (Nível Doutorado).
} 
entre escola e universidade no processo do ECS favorece a interlocução entre o campo científico/teórico com o campo prático/interventivo, representando uma oportunidade de relacionar as experiências vividas para que os distanciamentos, as divergências e as fragilidades sejam pesquisadas, debatidas, refletidas e compartilhadas e, desta maneira, as relações estabelecidas (encontros/confrontos) entre os agentes e as instituições envolvidas sejam beneficiadas.

Diante desse contexto, o ECS poderá permitir a problematização, a investigação e a análise da realidade a partir de uma prática reflexiva e colaborativa entre todos os atores envolvidos, sendo reconhecido como uma oportunidade de redimensionar as práticas, não apenas para os futuros professores, mas também para os profissionais que atuam na formação destes (professores orientadores e supervisores). Há então a possibilidade de transcender suas práticas e ressignificar suas identidades, tendo em vista que a arte de ensinar não é estática e finalizada, ao contrário, "ensinar exige a consciência do inacabamento", como enfatizado por Freire (1996) na reconhecida obra "Pedagogia da Autonomia".

No contexto da Educação Física (EF), o ECS também deve ser entendido como uma etapa da formação inicial em que se privilegia o processo de reflexão crítica do aluno frente à realidade com a qual está interagindo, valorizando os vínculos colaborativos, parcerias e relações, com o intuito de oportunizar e fortalecer a sua formação docente. Entretanto, ressalta-se que o ECS na formação inicial em EF apresenta características peculiares devido à especificidade da disciplina na sua conjuntura de atuação (Iza e Souza Neto, 2015; Silva Júnior e Oliveira, 2018).

Nessa linha de raciocínio, Gomes, Ferreira, Pereira e Batista (2013) ressaltam que os professores em geral apresentam características, competências e habilidades semelhantes. Porém, a especificidade da disciplina de EF e o seu contexto de atuação, sobretudo considerando o ambiente das aulas (fora da sala) e a sua dinâmica prática das atividades, os distinguem dos professores das outras disciplinas, o que proporciona uma identidade peculiar, na maioria das vezes mais atrativa, envolvente e agradável, comparando aos demais.

Ao longo dos últimos anos, observa-se que o ECS na EF obteve avanços na sua fundamentação teórica e metodológica, a partir da apropriação de teorias, estudos e tendências educacionais que se constituem como o alicerce pedagógico das disciplinas de estágio, assim como no direcionamento específico com a utilização e experimentação das 
abordagens pedagógicas da EF (Silva Júnior e Oliveira, 2018; Souza Neto, Benites, laochite e Borges, 2012).

Essa maior sustentação teórica e metodológica na área foi um aspecto importante e que acarretou o avanço na produção de conhecimento direcionado ao ECS na EF. Dentre tais investigações, destacam-se pesquisas que abordaram temáticas do ECS referentes: a formação inicial e/ou continuada dos acadêmicos e professores de EF (Benites, Souza Neto, Borges e Cyrino, 2012; Krug, Krug, Marques e Conceição, 2015; Moletta et al., 2013; Nunes e Fraga, 2006; Silveira, Batista e Pereira, 2014; Sodré e Neira, 2011), ao trato didáticopedagógico dos elementos relacionados às aulas de EF (Folle e Teixeira, 2012; Martiny e Gomes-da-Silva, 2014; Ribeiro, Folle, Farias e Nazario, 2015; Santos, Souza e Barbosa, 2013; Zotovici, Melo, Campos e Lara, 2013), a estrutura e organização do ECS, seja na escola ou na Instituição de Ensino Superior (IES) (Iza e Souza Neto, 2015; Silva, Souza e Checa, 2010), a modalidade de ensino no ECS, sobretudo na Educação à Distância e na Educação de Jovens e Adultos (Avance, Silva e Ventorim, 1999; Quaranta e Pires, 2013) e aos aspectos ligados à legislação do ECS na EF (Montiel e Pereira, 2011; Silva Júnior, Flores, Bisconsini, Anversa e Oliveira, 2016).

Considerando a conjuntura singular da disciplina e do professor de EF na escola, a importância e relevância do ECS em cursos de formação inicial em licenciatura, bem como os avanços de base teórica, metodológica e de legislação que sustentam, fundamentam e fortalecem o estágio, Neira (2012) afirma que normalmente observa-se uma desvalorização e um tratamento marginal às experiências formativas vividas fora da universidade, sobretudo o ECS e a Prática com Componente Curricular. Nesse sentido, os estágios na formação inicial de professores de EF deveriam ser vistos e representados como momentos significativos na vida dos estudantes, mas comumente são entendidos como um aspecto meramente formal, uma barreira a ser transposta (Aroeira, 2014; Neira, 2012).

Dentre alguns dos problemas e fragilidades encontradas, pode-se citar: a dificuldade de aproximação, colaboração e parceria entre a IES e a escola, acarretando no desenvolvimento do ECS com ações desarticuladas, que porventura não contempla as reais necessidades do contexto de atuação (Iza e Souza Neto, 2015), a configuração do ECS, por vezes oferecendo ênfase aos aspectos burocráticos e documentais em detrimento da prática pedagógica e do processo ensino-aprendizagem (Neira, 2012), a supervalorização de conteúdos apresentados de maneira desconectada das práticas e o desconhecimento das 
negociações, acordos e concessões que configuram o cenário escolar, sobretudo na EF (Borba e Wittizorecki, 2013).

Além destes apontamentos, destaca-se a participação pouco ativa dos professores de EF da escola, que não se reconhecem como integrantes no processo de formação (Benites, Cyrino e Souza Neto, 2012), a carência de participação assídua e colaborativa do professor orientador de ECS de forma a favorecer a aproximação entre IES e escola (Silva Júnior, Both e Oliveira, 2018), bem como a interação dos estagiários com os sujeitos envolvidos da escola (Aroeira, 2014).

Tendo em vista a constituição do ECS ao longo do processo educacional na formação inicial de professores de EF e as dificuldades que ainda se apresentam, principalmente nas relações estabelecidas entre o estagiário (visto como um elemento novo no contexto) e os demais personagens envolvidos, como professores, direção, equipe pedagógica, alunos e funcionários (elementos estabelecidos no seu contexto de atuação), questiona-se: $A$ configuração e organização do ECS, seja na IES ou na escola, exerce influência na atuação dos acadêmicos durante o estágio? As relações estabelecidas entre o estagiário e os personagens envolvidos (estagiários, professores, alunos, dentre outros) com o ECS limitam o trabalho pedagógico desenvolvido durante o estágio? A especificidade da disciplina de EF e o seu contexto de atuação são elementos que interferem nas relações entre estagiários e os demais agentes do ECS? No atual contexto em que o ECS se encontra na formação inicial de professores de EF, seria possível superar as dificuldades e limitações dessa prática sem se apropriar de um referencial teórico de análise?

Dessa forma, considerando tais questionamentos, o propósito do presente estudo é discutir o ECS na formação inicial de professores de EF na perspectiva da Teoria Configuracional de Norbert Elias $^{4}$, sobretudo no que diz respeito às relações entre estabelecidos-outsiders. Brandão (2003) destaca que os estudos de Elias podem ser utilizados como referencial teórico eficaz na compreensão de temas específicos da área educacional.

O estudo é caracterizado como um ensaio crítico fundamentado em Norbert Elias, no intuito de favorecer a compreensão do fenômeno estudado, bem como auxiliar na apresentação de possibilidades do ECS na formação inicial de professores de EF. Para isso,

\footnotetext{
4 De acordo com Elias (1980, 1994), a teoria das configurações, emerge de que os seres humanos interdependentes é premissa básica, fundamental e universal na compreensão dos fenômenos ligados à sociedade, na qual cada indivíduo pertence ou já teve ligado numa teia de pessoas. Ou seja, as relações entre pessoas são determinantes na configuração e na dinâmica de uma sociedade.
} 
utilizou-se como referencial teórico as obras de Norbert Elias, sobretudo "Introdução à Sociologia" (Elias, 1980), "A Sociedade dos Indivíduos" (Elias, 1994) e "Os estabelecidos e os outsiders: sociologia das relações de poder a partir de uma pequena comunidade" (Elias e Scotson, 2000), nas quais o autor faz suas análises e reflexões a partir da ideia das configurações de seres humanos interdependentes.

Marchi Jr. (2006) alerta que apesar de os estudos de Elias serem aplicáveis em múltiplos campos do conhecimento e importantes para a elaboração de conceitos e análises consistentes, deve-se ter cuidado e cautela no desencadeamento das interdependências e configurações, pois não utilizam normas convencionais e nem são autoexplicativas. É necessário considerar o tempo e o espaço histórico, bem como apresentar uma relação entre ter um conhecimento amplo e aprofundado sobre a sociedade (sociogênico) e um domínio da teoria utilizada (figuracional), no sentido de ampliar as linhas de pensamento, bem como a pluralidade de ideias, os sentimentos e os pensamentos.

\section{O Desenvolvimento do Tema}

Os estudos de Elias consideram as configurações de seres humanos interdependentes, nas quais o conceito de configuração se refere a um padrão alterável criado nas relações entre indivíduos em sociedade. As figurações e/ou configurações referem-se à coletividade humana não-estática e não-estagnada, porém em constante interrelação. A Teoria Elisiana revela que no mundo moderno as configurações se tornam cada vez mais evidentes e as relações entre as ações dos indivíduos da sociedade, nas quais um depende do outro, formam uma teia flexível de tensões de acordo com interesses dos grupos e/ou indivíduos e as relações de poder existentes (Elias, 1994).

Nesse sentido, pode-se fazer uma interlocução entre a teoria Elisiana e a constituição/funcionamento das instituições educacionais, pois estas são compostas por pessoas que apesar de serem indivíduos únicos, se relacionam com outras pessoas numa lógica e dinâmica de sociedade, e isso faz com que tal configuração e funcionamento sejam definidos a partir das relações entre indivíduos interdependentes. Nesse sentido, o conceito de rede (a rede de tecido) apresentado por Elias na Obra "A sociedade dos indivíduos" é fundamental para compreender as relações, aproximações, distanciamentos e confrontos entre os indivíduos em sociedade.

Nessa rede, muitos fios isolados ligam-se uns aos outros. No entanto, nem a totalidade da rede nem a forma assumida por cada um dos seus fios podem ser compreendidas 
em termos de um único fio, ou mesmo de todos eles, isoladamente considerados; a rede só é compreensível em termos da maneira como eles se ligam, de sua relação recíproca. Essa ligação origina um sistema de tensões para o qual cada fio isolado concorre, cada um de maneira um pouco diferente, conforme seu lugar e função na totalidade da rede. A forma do fio individual se modifica quando se alteram a tensão e a estrutura da rede inteira. No entanto essa rede nada é além de uma ligação de fios individuais; e, no interior do todo, cada fio continua a constituir uma unidade em si; tem uma posição e uma forma singulares dentro dele. (Elias, 1994, p.35)

De forma mais específica para o objetivo deste estudo, pode-se entender a escola como uma rede constituída por vários indivíduos (fios) que se inter-relacionam de forma dinâmica, promovendo aproximações, distanciamentos e confrontos geradores de conflitos nessa comunidade. Nessa conjuntura, são nítidas as relações de força e poder existentes entre os indivíduos pertencentes ao contexto escolar, fazendo com que a teia "estique", "encolha", "envergue", "amplie" e "cerceie" de acordo com as tensões envolvidas e as relações estabelecidas. Elias (1994, p. 20) reforça essas tensões ao afirmar que "[...] a vida dos seres humanos em comunidade certamente não é harmoniosa".

Diante dessas relações, têm-se os agentes do cenário da escola, que são compostos pela direção, equipe pedagógica, funcionários, professores e alunos. São eles os encarregados diretos pela formação e pelo movimento da rede, ou seja, a estrutura e o funcionamento da escola. Sendo assim, se apropriando do conceito e exemplificação de rede proposto por Norbert Elias, pode-se entender que os indivíduos que compõe a escola são elementos fundamentais na sua constituição, no delineamento e no direcionamento, seja administrativo e/ou pedagógico.

Nesse enquadramento, as relações entre os indivíduos no contexto escolar são determinantes para a estruturação, a organização e o funcionamento das instituições de ensino. Para aprofundar tal discussão, serão apresentados dois conceitos propostos e enfatizados por Elias em suas obras: configuração e poder. Vinha (2000) revela que os conceitos de configuração e poder em Elias estão diretamente interligados e relacionados. Para o autor, a configuração de seres humanos interdependentes e as forças que compreendem o poder determinam as relações, as tensões e os conflitos de indivíduos e sociedades. 
No contexto das configurações, Elias (1994, p. 27) afirma que "[...] uma das condições fundamentais da existência humana é a presença simultânea de diversas pessoas interrelacionadas", na qual não se podem considerar as pessoas como seres singulares e isolados. Nesse contexto, ressalta que "[...] cada pessoa singular está realmente presa; está presa por viver em permanente dependência funcional de outras; ela é um elo nas cadeias que ligam outras pessoas, assim como todas as demais, direta ou indiretamente, são elos nas cadeias que a prendem" (Elias, 1994, p. 23).

No mesmo sentido em que exemplificou a rede de tecido, Elias (1994, p. 25) apresenta outros exemplos para ilustrar as configurações:

Não se compreende uma melodia examinando-se cada uma de suas notas separadamente, sem relação com as demais. Também sua estrutura não é outra coisa senão a das relações entre as diferentes notas. Dá-se algo semelhante com a casa. Aquilo a que chamamos sua estrutura não é a estrutura das pedras isoladas, mas a das relações entre as diferentes pedras com que ela é construída; é o complexo das funções que as pedras têm em relação umas às outras na unidade da casa. Essas funções, bem como a estrutura da casa, não podem ser explicadas considerando-se o formato de cada pedra, independente de suas relações mútuas; pelo contrário, o formato das pedras só pode ser explicado em termos de sua função em todo o complexo funcional, a estrutura da casa. Deve-se começar pensando na estrutura do todo para se compreender a forma das partes individuais. Esses e muitos outros fenômenos têm uma coisa em comum, por mais diferentes que sejam em todos os outros aspectos: para compreendê-los, é necessário desistir de pensar em termos de substâncias isoladas únicas e começar a pensar em termos de relações e funções.

Da mesma forma, pode-se fazer referência ao olhar e analisar a instituição escolar, na qual a sua configuração e as relações estabelecidas entre os agentes que ali estão determinam a sua organização e o seu funcionamento. Quanto ao poder, Elias (1994) enfatiza que tal elemento se constitui como efeito das relações entre indivíduos e que não se concebe de forma concreta e simples. Nesse sentido, complementa que é "uma expressão um tanto rígida e indiferenciada para designar a extensão especial da margem individual de ação associada a certas posições sociais, expressão designativa de uma oportunidade social particularmente ampla de influenciar a autorregularão e o destino de outras pessoas" (1994, p. 50). 
Considerando a complexidade e multiplicidade das configurações e das relações de poder que emergem e se concretizam no contexto escolar. Pesquisas de cunho sociológico e educacional, sobretudo com base no referencial Elisiano, vêm sendo desenvolvidas no sentido de ampliar o olhar a respeito das diferenças de organização estabelecidas e concretizadas, seja de modo impositivo ou democrático, e das relações de poder e hierarquia que são frequentemente visualizadas nas instituições escolares (Botler, 2010; Rocha e Fernandes, 2014; Tavares, 2012).

As discussões e possibilidades para o ECS na EF e suas relações/aproximações com a Teoria Configuracional de Norbert Elias se colocam como um ponto de partida muito rico para estudos dessa natureza, sendo que a prática pedagógica poderá se enriquecer e ganhar em abrangência e significado formativo. Nos últimos anos observa-se um avanço, ainda que limitado, quanto à produção de conhecimento na EF com análises dos fenômenos estudados à luz da teoria de Norbert Elias (Silva Júnior, Both e Oliveira, 2018).

Isso se apresenta importante como forma de valorizar a originalidade desse estudo, mas para, além disso, mostrar a relevância de tratar o ECS como uma forma de pesquisa (Pimenta e Lima, 2012), na qual os estudantes possam cumprir essa prática pedagógica, reforçando a articulação da teoria com a prática, de forma crítica e reflexiva, respaldados por um referencial teórico consistente.

Em um breve levantamento na literatura, foram reveladas pesquisas fundamentadas em Elias para compreender temas relativos ao Esporte (Dias, 2010; Souza, Starepravo e Marchi Jr., 2011; 2014), ao Esporte e lazer (Marchi Jr., 2006; Starepravo, Souza e Marchi Jr., 2012) e ao mapeamento de estudos na EF (Medeiros e Godoy, 2009).

Além desses, pode-se citar os vários trabalhos e pesquisas sobre EF veiculados nos Simpósios Internacionais de Processo Civilizador. Em uma pesquisa realizada por Lima e Souza (2010), cujos objetivos foram identificar e analisar a produção científica da EF publicada nos Simpósios do Processo Civilizador, os autores constataram que em doze edições desse evento foram encontrados 512 trabalhos abordando a EF em suas diversas vertentes, como educação, esporte, lazer, dentre outros. No entanto, os autores revelaram que para vários desses trabalhos apresentados no evento, o referencial teórico é utilizado de forma rasa, inconsistente e não apropriada ao fenômeno estudado.

Nesse sentido, acerca dos estudos que envolvem os fenômenos sociais da EF, Marchi Jr. (2006) alerta para a necessidade de superação do tradicionalismo superficial de boa parte 
das pesquisas na área, e enfatiza a importância e contribuição da aquisição e utilização de referenciais teóricos de análises consistentes e coerentes com a investigação.

Apesar desse crescimento nas pesquisas da área, ainda são escassos os estudos que utilizam a teoria Elisiana como suporte teórico e metodológico para embasar as análises das investigações no contexto educacional e/ou escolar da EF e, principalmente, relacionado com o ECS na formação de professores de EF (Silva Júnior e Oliveira, 2018). Por outro lado, no cenário da educação de forma geral, foram constatadas algumas iniciativas que se apropriaram da teoria de Elias, por exemplo, as pesquisas de Brandão (2003), Leão (2007), Hunger, Rossi e Souza Neto (2011) e Tavares (2012).

Considerando o panorama do ECS na formação inicial de professores de EF e a relevância/pertinência da base teórica e metodológica de Norbert Elias para os estudos do campo educacional, já mencionadas e discutidas neste texto. A seguir será dada ênfase nas aproximações, inter-relações, incursões e inferências com as quais o referencial Elisiano permite dialogar e discutir no contexto pesquisado.

Para exemplificar as questões relacionadas às configurações e relações de poder, na obra denominada "Os Estabelecidos e os Outsiders: sociologia das relações de poder a partir de uma pequena comunidade", Elias e Scotson (2000) apresentaram as relações de poder entre dois grupos de moradores de uma pequena comunidade da Inglaterra, no final dos anos de 1950.

No estudo, dois grupos de moradores de uma comunidade possuíam características iguais ou semelhantes referentes ao tipo de ocupação, religião, educação, nacionalidade, classe social, cor e raça. Contudo, o tempo de moradia no vilarejo foi considerado fator determinante de domínio e exercício de poder dos mais antigos frente aos mais novos. Os membros do grupo dos moradores mais antigos se conheciam há muito tempo e seu relacionamento era situado com estilo próprio e regras particulares, as quais eram definidas por tradição, autoridade e influência dentro do vilarejo industrial; Elias denominou-os de Estabelecidos. O grupo de moradores mais novos, denominados de Outsiders era estigmatizado como pessoas de valor inferior pelos Estabelecidos, tratando-os como indivíduos excluídos do grupo, "os de fora" (Elias e Scotson, 2000).

De acordo com Sallas (2001), essa pesquisa de Norbert Elias se apresenta como de grande relevância para as Ciências Sociais, considerando a possibilidade de ser visualizada, incorporada, experimentada e comparada em outros contextos e realidades. $O$ referencial teórico de Norbert Elias, sobretudo o das relações Estabelecidos-Outsiders foi tomado como 
base para se traçar considerações acerca das relações estabelecidas no ECS na formação inicial de professores de EF. No caso da discussão apresentada neste trabalho, far-se-á a inferência dos estagiários como os Outsiders e os agentes da escola (professores, diretores, equipe pedagógica, funcionários e alunos) como os Estabelecidos.

Tal dedução de personagens se dá pela dificuldade que os estagiários apresentam em desenvolver com autonomia suas ações, atividades e práticas pedagógicas durante a execução do ECS. Principalmente pelo fato de serem pessoas novas no contexto escolar e estarem frente a frente com indivíduos que normalmente já apresentam uma história, um laço maior de envolvimento, uma raiz fixada e/ou uma cultura estabelecida no ambiente.

Nesse sentido, as relações de interdependência entre os envolvidos no estágio podem apresentar práticas negativas de exercitar o poder. Nessas práticas, os agentes da escola, principalmente o professor, que é levado à construção de um habitus ${ }^{5}$, já não estranha determinadas práticas e convenções, as quais ele próprio criticava em sua formação inicial, inclusive durante a realização do seu ECS. No entanto, pouco tempo depois de ingressar na atuação profissional, muitos acabam por reproduzir as mesmas práticas dos professores mais antigos (estabelecidos) (Silva Júnior, Both e Oliveira, 2018).

Souza Neto, Benites e Silva (2010), em um estudo a respeito da constituição do habitus profissional do professor de EF, afirmaram que as práticas, as rotinas e os esquemas são os principais aspectos geradores do habitus do professor, e no caso da EF os saberes práticos induzem à rotina e a diminuição da gama de possibilidades e riqueza promovida pelas vivências a partir da disciplina EF.

Tal panorama limita e dificulta a atuação do estagiário, pois ele é normalmente considerado um "estranho" ou "fora de contexto", e ao chegar no ambiente da escola, depara-se com uma realidade de difícil entrosamento, repleta de obstáculos, barreiras e entraves, que extrapolam a tarefa de exclusivamente ministrar aulas, o que, por vezes, ocasiona ações pedagógicas aquém do previsto para o contexto escolar da EF.

Sobre isso, Ball (1989) na obra La micropolitica de la escuela: hacía una teoría de la organización escolar, revela que além do contexto específico pedagógico, a escola é permeada por "elementos micropolíticos", como conflitos, acordos, outorgas, dentre outros, que influenciam direta ou indiretamente na ação pedagógica docente. No mesmo direcionamento, mas de forma específica para o trabalho do professor de EF, Borba e

\footnotetext{
5 O conceito de habitus, em Elias, é fruto da relação de interdependência entre indivíduo e sociedade, no qual deve ser considerado o processo histórico, a complexidade e a dinâmica que envolve as relações entre os indivíduos em sociedade (Elias, 1994).
} 
Wittizorecki (2013) acrescentam que, em virtude da singularidade da área e do contexto de atuação, o professor dessa disciplina possui um cargo instável por lidar com uma complexidade de conflitos e disputas na sua atuação profissional.

Nesse jogo de conflitos, ao entrar na escola, o estagiário pode mexer com estruturas e ampliar as tensões envolvidas, de forma que o professor da disciplina, bem como os outros agentes do contexto escolar possam se sentir ameaçados. Assim, como forma de defesa, os estabelecidos podem exercer relações de poder desproporcionais, fazendo com que os estagiários cumpram o seu papel de forma simplista, fortalecendo dessa forma a ideia apresentada na teoria Elisiana (Os Estabelecidos e os Outsiders). De acordo com Elias e Scotson (2000), os mais novos acabam por aceitar a configuração estabelecida por pertencer a um grupo de menor representatividade social.

Nesse sentido, considerando o conceito de jogo ${ }^{6}$ proposto por Norbert Elias, essa relação mostra certo desiquilíbrio entre as partes, numa distribuição desigual de poder, a qual certamente reduzirá a autonomia do futuro professor de EF durante a realização do ECS. De acordo com Elias (1980, p. 81), "os modelos de jogos ajudam a mostrar como os problemas sociológicos se tornam mais claros e como é mais fácil lidar com eles se os reorganizarmos em termos de equilíbrio". No mesmo sentido, o autor complementa que "[...] se diminuírem as diferenças de poder entre os dois níveis, a dependência do nível mais alto em relação ao mais baixo tornar-se-á mais forte - e sendo mais fortes, todos os participantes têm dela maior consciência" (Elias, 1980, p. 97).

Por outro lado, é importante destacar que tendo em vista a experiência do professor de EF supervisor de estágio, o seu conhecimento sobre a realidade da escola, dos seus alunos e dos demais determinantes que podem implicar a prática pedagógica das aulas de EF, assim como a sua posição de profissional, exige-se desse professor a atribuição de ser o responsável legal por sua(s) turma(s), o que requer responsabilidade, compromisso, ética, respeito, determinação, dentre outros aspectos. Dessa forma, é natural que o professor de EF da escola tenha uma posição de maior controle frente ao estagiário. No entanto, tal colocação deve possibilitar uma relação equilibrada de poder, na qual sejam valorizadas as trocas, as relações harmônicas, as parcerias, de forma que se reconheça o processo como

\footnotetext{
${ }^{6}$ Elias $(1980,1984)$ reforça que o jogo é caracterizado a partir da ideia de que não pode ser disputado sozinho e de que o movimento de um jogador (indivíduo) interfere ou varia relativamente de acordo com seu adversário. A concepção de jogo na/em sociedade permite que as pessoas possam se transformar, crescer, adaptar, ajustar, aproximar, distanciar conforme a dinâmica exercida e os posicionamentos realizados.
} 
"via de mão dupla", ou seja, que todos possam participar ativamente do sistema, num direcionamento horizontal entre os envolvidos (Freire, 1996).

Nesse sentido, Elias (1980) enfatizou a importância do equilíbrio do poder nas relações humanas, superando os modelos bipolares por multipolares, ou seja, valorizando e estimulando a divisão de forças e poderes na sociedade. "Os modelos poderão ajudar relativamente a obtenção de uma melhor compreensão do tal equilíbrio de poder, não como uma ocorrência extraordinária, mas como uma ocorrência cotidiana" (p. 80). A ideia de Elias reafirma a lógica de indivíduos interdependentes, que se relacionam, exercem interferência no(s) outro(s), causa(m) conflitos e tensões, mas que dependendo da configuração e da forma que ocorrem as relações, poderão impactar de maneira positiva e/ou negativa no cenário em questão, nesse caso, no ECS na formação inicial de professores de EF.

Nessas relações de força e de distribuição de poder é importante que o professor de EF saiba agir com os preceitos da formação profissional, como responsabilidade, compromisso e ética. Mas, além disso, é imprescindível que esteja capacitado para a colaboração com o estagiário, bem como se sinta integrante do processo de formação do futuro professor de EF.

Pesquisas como as de Neira (2012); Benites, Cyrino e Souza Neto (2013) e Aroeira (2014) constataram que há necessidade de maior integração entre os envolvidos no processo de ECS, e ainda destacaram que a falta de participação mais ativa dos docentes da escola é a principal queixa dos estagiários. Muitas vezes, o fato de ter um estagiário é entendido pelo docente supervisor como um momento de descanso, assim possivelmente não oferece a contribuição esperada no processo de formação do futuro docente. Normalmente, fatores como a desmotivação, acomodação e/ou estabilidade, o receio de sair da zona de conforto, a visão limitada da relação teoria-prática, aliados à falta de um mecanismo de controle e cobrança no atual sistema de ensino, pode influenciar negativamente na formação dos futuros docentes, pois se assume, desde essa etapa de formação, a condição de livre exercício profissional ao reconhecê-la no setor educacional público.

Nesse sentido, destaca-se a necessidade de atuação mais efetiva de todas as partes envolvidas, para minimizar os efeitos da adaptação e possibilitar ao estagiário, condições adequadas para que possa exercer a sua prática com efetividade e com vistas a atingir os objetivos propostos pelo estágio. Da mesma forma, acredita-se também na necessidade de aproximação e maior articulação entre todos os envolvidos no estágio (alunos, professores 
orientadores, professores supervisores, escola-campo e universidade) como maneira de busca de uma prática que efetive a possibilidade do aluno vivenciar um ambiente propício de aprendizagem ao futuro docente, por meio de experiências percebidas de forma positiva, que os estimulem a ações reflexivas junto às possibilidades de práticas pedagógicas (Bisconsini, Flores e Oliveira, 2016).

Para que isso ocorra, outro aspecto importante a ser considerado na realização do ECS, e que Norbert Elias menciona no seu estudo, é a questão do tempo. O período de tempo permanecido/vivido numa localidade determina as relações de poder e hierarquia que os indivíduos estabelecem uns com os outros (Elias e Scotson, 2000). Nesse sentido, além do tempo de "residência" dos já estabelecidos na escola, a configuração do tempo de duração do ECS é de essencial importância, sendo que períodos mais extensos de estágio favorecem a criação de relações mais próximas e harmônicas com os agentes do contexto escolar (Aroeira, 2014; Pimenta e Lima, 2012).

Seguindo essa linha de raciocínio, é preferível que a configuração do ECS possibilite a vivência das ações pedagógicas em uma turma para cada nível de ensino, em maior tempo de duração, em vez de distribuir a carga horária do estágio para várias turmas em período reduzido. Para que se criem o vínculo, a parceria, o controle, os ajustes, os acordos, as rotinas e outros, o tempo de duração do estágio é requisito essencial, no entanto, mesmo assim não é garantia que isso se efetive.

No sentido de uma configuração interdependente, é elementar compreender o ECS como uma atividade integrada ao Projeto Pedagógico do Curso e que deve ser trabalhada articulando e relacionando todos os componentes curriculares na formação inicial, no intuito de explorar e utilizar os diversos saberes e conhecimentos do curso no ECS e vice-versa (Pimenta e Lima, 2012). Dessa forma, torna-se fundamental possibilitar uma configuração de ECS que favoreça a aproximação entre o Projeto Pedagógico do Curso da IES e o Projeto Político Pedagógico da escola, bem como dos conhecimentos aprendidos e das práticas vivenciadas.

Como forma de síntese e de reiteração das discussões apresentadas, Hunger et al., (2011) revelam que na escola o modelo estabelecido com base em configurações poderá superar conceitos de superioridades estáticas, possibilitando relações mais harmônicas e dependentes entre os elementos do contexto escolar. Os autores enfatizam que essas relações são indispensáveis e nenhum indivíduo é inteiramente autônomo, considerando que as particularidades individuais estão sempre firmadas nas figurações sociais. 


\section{Considerações Finais}

O modelo de configurações de seres humanos interdependentes, proposto por Norbert Elias e utilizado neste trabalho, permitiu demonstrar como essas relações se dão e podem ser mais bem trabalhadas no ECS na formação inicial de professores de EF. A partir da constatação de que a escola e a universidade são, nitidamente, vistas como teias complexas de relações interdependentes e de poder, possibilita-se inferir que o ECS na formação inicial de professores de EF deve constituir-se como um espaço de relações mais próximas entre todos os elementos que fazem parte desse processo de ensino na formação inicial.

Nesse sentido, foi possível identificar que o modelo de configurações de seres humanos interdependentes, sobretudo o das relações entre os "Estabelecidos" e os "Outsiders" apresentado por Elias, poderá ser utilizado e aplicado em outros contextos e realidades educacionais como forma de investigação para outras pesquisas. No entanto, apesar de embasado e fundamentado, o presente ensaio limitou-se às reflexões e especulações teóricas. Dessa forma, sugere-se que esse referencial seja o "estímulo inicial" para a realização de pesquisas de campo, diretamente com os agentes evolvidos com o ECS, no intuito de investigar tais relações/incursões.

Levantou-se que os conflitos e as tensões ocorridos durante o processo formativo do ECS entre os futuros professores de EF (outsiders) e os demais integrantes do contexto escolar (estabelecidos) fazem parte de um jogo, no qual existem disputas de poder, objetivando uma posição privilegiada no contexto formativo e de atuação. Mas para que isso ocorra é necessário que haja equilíbrio das forças utilizadas, de forma que o estagiário possa enxergar os agentes da escola como parceiros, colaboradores e participantes do processo e vice-versa.

No caso da área da $E F$, considerando a sua especificidade e o âmbito de atuação, tais disputas de poder podem ser visualizadas de forma mais intensa e frequente, muitas vezes denigrindo ou "manchando" a imagem da área. Assim, ressalta-se a necessidade da valorização e fortalecimento do ECS na formação dos futuros professores de EF, no intuito de resguardar a área e a disciplina de EF.

Considerando o exposto, conclui-se que o ECS é uma prática dinâmica, complexa e de suma importância na formação inicial dos professores de EF. No entanto, as discussões apresentadas no estudo e referendadas a partir do referencial teórico de Norbert Elias, reforçam a importância das configurações e das relações de indivíduos interdependentes. Dessa forma, a complexidade desse processo formativo exige o domínio de competências e 
habilidades de todos os envolvidos (professores da IES e das escolas e estagiários), no intuito de possibilitar as instruções, as trocas de conhecimentos, os relacionamentos e as reflexões sobre a atuação pedagógica.

Por fim, o estudo e a análise crítica da proposta possibilitaram apontamentos para o ECS na formação de professores de EF, como: estabelecimento de parcerias de cooperação com os órgãos educacionais; realização de eventos; execução de reuniões periódicas; desenvolvimento de planejamento coletivo, realização da prática como componente curricular de forma mais aplicada no contexto escolar, dentre outras.

\section{Agradecimentos}

Agradecimentos à Fundação Araucária de Apoio ao Desenvolvimento Científico e Tecnológico do Estado do Paraná e à Coordenação de Aperfeiçoamento de Pessoal de Nível Superior (CAPES) pelo apoio a esta pesquisa.

\section{Referências}

Aroeira, Kalline Pereira. (2014). Estágio Supervisionado e possibilidades para uma formação com vínculos colaborativos entre a universidade e a escola. Em Maria Isabel Almeida, e Selma Garrido Pimenta (orgs.), Estágio Supervisionado na formação docente: educação básica e educação de jovens e adultos (pp. 113-150). São Paulo: Cortez.

Avance, Alessandro, Silva, Alex Aziel da e Ventorim, Silvana. (1999). Estágio Supervisionado em Educação Física: uma experiência com educação de jovens e adultos. Motrivivência, $11(13), \quad 1-13 . \quad$ Recuperado de https://periodicos.ufsc.br/index.php/motrivivencia/article/view/14407/13210

Ball, Stephen J. (1989). La micropolítica de la escuela: hacia una teoría de la organización escolar. Barcelona: Paidós.

Benites, Larissa Cerignoni, Cyrino, Marina e Souza Neto, Samuel de. (2013). Estágio curricular supervisionado: a formação do professor-colaborador. Olh@res, 1(1), 116140. Recuperado de http://www.olhares.unifesp.br/index.php/olhares/article/view/32/5

Benites, Larissa Cerignoni, Souza Neto, Samuel de, Borges, Cecília e Cyrino, Marina. (2012). Qual o papel do professor colaborador no contexto do estágio curricular supervisionado na educação física? Revista Brasileira de Ciência e Movimento, 20(4), 13-25. Recuperado de https://portalrevistas.ucb.br/index.php/RBCM/article/view/3286/2282

Bisconsini, Camila Rinandi, Flores, Patric Paludett e Oliveira Amauri Aparecido Bássoli. (2016). Formação inicial para a docência: o estágio curricular supervisionado na visão de seus coordenadores. Journal of Physical Education, 27(1), 1-13. Recuperado de http://www.periodicos.uem.br/ojs/index.php/RevEducFis/article/view/28577/16720 
Borba, Jônatas Costa Brasil e Wittizorecki, Elisandro Schultz. (2013). Micropolítica escolar e o trabalho docente em educação física: negociações, acordos e concessões. Revista Didática Sistêmica, (Edição Especial), 55-68. Recuperado de https://www.seer.furg.br/redsis/article/view/4169/2715

Botler, Alice Happ. (2010). Cultura e relações de poder na escola. Educação \& Realidade, 35(2), 187-206. Recuperado de http://seer.ufrgs.br/index.php/educacaoerealidade/article/view/8708/9460

Brandão, Carlos da Fonseca. (2003). Norbert Elias: formação, educação e emoções no processo de civilização. Petrópolis: Vozes.

Dias, Cleber. (2010). A sociologia figuracional e os estudos do esporte. Revista Brasileira de Ciência do Esporte, 31(2), 155-169. Recuperado de http://revista.cbce.org.br/index.php/RBCE/article/view/524

Elias, Norbert. (1994). A sociedade dos indivíduos. Río de Janeiro, Brasil: Zahar.

Elias, Norbert. (1980). Introdução à sociologia. Lisboa: Edições 70.

Elias, Norbert e Scotson, John L. (2000). Os estabelecidos e os outsiders: sociologia das relações de poder a partir de uma pequena comunidade. Rio de Janeiro: Zahar.

Folle, Alexandra e Teixeira, Fabiano Augusto. (2012). Motivação de escolares das séries finais do ensino fundamental nas aulas de Educação Física. Revista da Educação Física/UEM, 23(1), 37-44. $\quad$ Recuperado de http://www.periodicos.uem.br/ojs/index.php/RevEducFis/article/view/12202/9328

Freire, Paulo. (1996). Pedagogia da autonomia (30ª ed.). São Paulo: Paz e Terra.

Gomes, Patrícia Maria Silva, Ferreira, Cátiia Patrícia Ferreira, Pereira, Ana Luísa e Batista, Paula Maria Fazendeiro. (2013). A identidade profissional do professor: um estudo de revisão sistemática. Revista Brasileira de Educação Física e Esporte, São Paulo, 27(2), 247-267. Recuperado de http://www.revistas.usp.br/rbefe/article/view/58565/61586

Hunger, Dagmar, Rossi, Fernanda e Souza Neto, Samuel de. (2011). A teoria de Norbert Elias: uma análise do ser professor. Educação e Pesquisa, 37(4), 697-710. Recuperado de http://www.scielo.br/pdf/ep/v37n4/a02v37n4.pdf

Iza, Dijnane Fernanda Vedovatto e Souza Neto, Samuel. (2015). Os desafios do estágio curricular supervisionado em educação física na parceria entre universidade e escola. Movimento, 21(1), 111-124. Recuperado de http://seer.ufrgs.br/index.php/Movimento/article/view/46271/33336

Krug, Hugo Norberto, Krug, Rodrigo de Rosso, Marques, Marta Nascimento e Conceição, Victor Julierme Santos. (2015). Ser professor na escola: de aluno a professor no estágio curricular supervisionado na licenciatura em Educação Física. Linhas, 16(30), 248-269.

Recuperado de http://www.revistas.udesc.br/index.php/linhas/article/view/1984723816302015248/pdf 5 $\underline{9}$ 
Leão, Andréa Borges. (2007). Norbert Elias \& a educação. Belo Horizonte, Brasil: Autêntica.

Lima, Dayene Mayara Mendes e Souza, Edilson Fernandes. (2010). Os marcos conceituais Elisianos nas pesquisas sobre educação física no Brasil. Anais do XVIII Congresso de Iniciação Científica da UFPE, Recife, Brasil.

Marchi Jr., Wanderley. (2006). A educação física e o campo científico: repensando as possibilidades de pesquisa sobre o esporte e o lazer. Em Fernando Marinho Mezzadri, Fernando Renato Cavichiolli e Doralice Lange de Souza (org.), Esporte e lazer: subsídios para o desenvolvimento e a gestão de políticas públicas (pp. 29-42). Jundiaí: Fontoura.

Martiny, Luis e Gomes-da-silva, Pierre. (2014). A transposição didática na educação física escolar: a reflexão na prática pedagógica dos professores em formação inicial no estágio supervisionado. Revista da Educação Física/UEM, 25(1), 81-94. Recuperado de http://www.scielo.br/pdf/refuem/v25n1/1983-3083-refuem-25-01-00081.pdf

Medeiros, Cristina Carta Cardoso e Godoy, Letícia. (2009). As referências de Pierre Bourdieu e Norbert Elias na Revista Brasileira de Ciências do Esporte: mapeando tendências de apropriação e de produção de conhecimento na área da educação física (1979-2007). Revista Brasileira de Ciência do Esporte, 30(2), 199-214. Recuperado de http://revista.cbce.org.br/index.php/RBCE/article/view/445/361

Moletta, Andréia Fernanda, Teixeira, Fabiano Augusto, Folle, Alexandra, Nascimento, Juarez Vieira do, Farias, Gelcemar de Oliveira e Marinho, Alcyane. (2013). Momentos marcantes do estágio curricular supervisionado na formação de professores de educação física. Pensar a Prática, 16(3), 715-730. Recuperado de https://www.revistas.ufg.br/fef/article/view/18705/15246

Montiel, Fabiana e Pereira, Flávio Medeiros. (2011). Problemas evidenciados na operacionalização das 400 horas de estágio curricular supervisionado. Revista da Educação Física/UEM, 22(3), 421-432. Recuperado de http://www.periodicos.uem.br/ojs/index.php/RevEducFis/article/view/10391/7768

Neira, Marcos Garcia. (2012). Proposições para o estágio disciplinar na formação de professores de Educação Física. Nascimento, Juarez e Farias, Gelcemar Oliveira (Org), Construção da identidade profissional em Educação Física: da formação a intervenção (pp. 177-202). Florianópolis: Editora da Udesc.

Nunes, Rute Viégas e Fraga, Alex Branco. (2006). "Alinhamento astral": o estágio docente na formação do licenciado em educação física na ESEF/UFRGS. Pensar a Prática. 9(2), 297-311. Recuperado de https://www.ufrgs.br/polifes/wpcontent/uploads/2013/03/Alinhamento-Astral.pdf

Pimenta, Selma Garrido e Lima, Maria Socorro Lucena. (2012). Estágio e docência (7ª̣. ed.). São Paulo: Cortez.

Quaranta, André Marsiglia e Pires, Giovani De Lorenzi. (2013). Histórias de vida e experiências docentes no estágio supervisionado de licenciandos em educação física modalidade EAD. Movimento, 19(2), 185-205. Recuperado de http://www.seer.ufrgs.br/index.php/Movimento/article/view/23488/25260 
Ribeiro, Vandressa Teixeira, Folle, Alexandra, Farias, Gelcemar Oliveira e Nazario, Patrik Felipe. (2015). Preocupações pedagógicas e competência profissional de estudantes de educação física em situação de estágio. Revista da Educação Física/UEM, 26(1), 59-68.

Recuperado

de http://www.periodicos.uem.br/ojs/index.php/RevEducFis/article/view/21835/14982

Rocha, Maria Custódia Jorge e Fernandes, Amália Gonçalves. (2014). As relações de poder na escola pública: um estudo de caso. Práxis Educativa, 9(1), 167-195. Recuperado de http://www.revistas2.uepg.br/index.php/praxiseducativa/article/view/4986/3912

Sallas, Ana Luiza Fayet. (2001). Resenha Elias, Norbert \& Scotson, John L. 2000. Os Estabelecidos e os Outsiders: Sociologia das Relações de Poder a partir de uma Pequena Comunidade. Campos - Revista de Antropologia Social, 1, 217-220. Recuperado de http://revistas.ufpr.br/campos/article/download/1561/1309

Santos, Rafaela Gomes dos, Souza, Adriano Lopes e Barbosa, Franck Nei Monteiro. (2013). Estágio Supervisionado I: o desafio da avaliação nas aulas de educação física escolar. Pensar a Prática, 16(2), 501-518. Recuperado de https://www.revistas.ufg.br/fef/article/view/17384/14649

Silva Júnior, Arestides Pereira da, Both, Jorge, e Oliveira, Amauri Aparecido Bássoli de. (2018). Configurações e relações estabelecidas no estágio curricular supervisionado de Educação Física. Journal of Physical Education, 29(1), 1-13. Recuperado de http://www.periodicos.uem.br/ojs/index.php/RevEducFis/article/view/36081/7513751376 $\underline{74}$

Silva Júnior, Arestides Pereira da, Flores, Patric Paludett, Bisconsini, Camila Rinaldi, Anversa, Ana Luíza Barbosa e Oliveira, Amauri Aparecido Bássoli de. (2016). Estágio curricular supervisionado na formação de professores em educação física: uma análise da legislação a partir da resolução CFE 03/1987. Pensar a Prática, 19(1), 1-14. Recuperado de https://www.revistas.ufg.br/fef/article/view/34854/pdf

Silva Júnior, Arestides Pereira da, e Oliveira, Amauri Aparecido Bássoli de. (2018). Estágio curricular supervisionado na formação de professores de educação física no Brasil: uma revisão sistemática. Movimento, 24(1), 77-92. Recuperado de http://www.seer.ufrgs.br/index.php/Movimento/article/view/67071/47795

Silva, Sheila Aparecida Pereira dos Santos, Souza, César Augusto Fernandes de e Checa, Felipe Marques. (2010). Situação do estágio supervisionado em IES privadas da grande São Paulo. Motriz, 16(3), 682-688. Recuperado de http://www.scielo.br/pdf/motriz/v16n3/a16v16n3.pdf

Silveira, Gonçalo Carlos, Batista, Paula Maria e Pereira, Ana Luísa. (2014). O perfil do professor cooperante no contexto da supervisão de estágio profissional: um estudo de revisão sistemática da literatura. Revista da Educação Física/UEM, 25(2), 309-321. Recuperado de http://www.scielo.br/pdf/refuem/v25n2/1983-3083-refuem-25-0200309.pdf 
Sodré, Marina de Lima e Neira, Marcos Garcia. (2011). A Formação de professores de Educação Física na Universidade de São Paulo: análise das experiências de estágio disciplinar. Caderno de Educação Física, 10(19), 11-18. Recuperado de http://www.gpef.fe.usp.br/teses/sodre 01.pdf

Souza, Juliano, Starepravo, Fernando Augusto e Marchi Junior, Wanderley. (2014). A sociologia configuracional de Norbert Elias - potencialidades e contribuições para o estudo do esporte. Revista Brasileira de Ciência do Esporte, 36(2), 429-445. Recuperado de http://www.scielo.br/pdf/rbce/v36n2/0101-3289-rbce-36-02-00429.pdf

Souza, Juliano, Starepravo, Fernando Augusto e Marchi Junior, Wanderley. (2011). O processo de constituição histórico-estrutural do subcampo esportivo do xadrez: uma análise sociológica. Movimento, 17(2), 93-113. Recuperado de http://seer.ufrgs.br/index.php/Movimento/article/view/16516/13132

Souza Neto, Samuel de, Benites, Larissa Cerignoni e Silva, Mellissa Fernanda Gomes da. (2010). Da escola de ofício a profissão educação física: a constituição do habitus profissional de professor. Motriz, 16(4), 1033-1044. Recuperado de http://www.scielo.br/pdf/motriz/v16n4/a24v16n4.pdf

Souza Neto, Samuel, Benites, Larissa Cerignoni, laochite, Roberto Tadeu e Borges, Cecilia. O estágio supervisionado como prática profissional, área de conhecimento e locus de construção da identidade do professor de Educação Física. Nascimento, Juarez e Farias, Gelcemar Oliveira (Org). Construção da identidade profissional em Educação Física: da formação a intervenção. Florianópolis: Editora da Udesc.

Starepravo, Fernando Augusto, Souza, Juliano e Marchi Junior, Wanderley. (2012). A teoria dos jogos competitivos de Norbert Elias como alternativa à leitura das políticas públicas de esporte e lazer no Brasil. Revista Brasileira de Educação Física e Esporte, 26(4), 657-665. Recuperado de http://www.scielo.br/pdf/rbefe/v26n4/v26n4a10.pdf

Tavares, Davi Kiermes. (2012). O poder como inspiração: Elias, Foucault e a educação escolar. Revista Eletrônica Multidisciplinar Pindorama do Instituto Federal de Educação, Ciência e Tecnologia da Bahia, 2(2), 1-22. Recuperado de http://www.publicacoes.ifba.edu.br/index.php/Pindorama/article/view/384

Vinha, Marina. (2000). O conceito de configuração e poder em Norbert Elias. Revista Conexões, (5), 48-50. Recuperado de https://periodicos.sbu.unicamp.br/ojs/index.php/conexoes/article/view/8638149/5825

Zotovici, Sandra Aparecida, Melo, Janaína Benasse, Campos, Márcia Zendron de e Lara, Larissa Michelle. (2013). Reflexões sobre o estágio supervisionado no curso de licenciatura em Educação Física: entre a teoria e a prática. Pensar a Prática, 16(2), 568-582. Recuperado de https://www.revistas.ufg.br/fef/article/view/16593/14610 